\title{
Evaluation of incompatibility in measurement of erythrocyte sedimentation rate by two different modes of automated analyzer and demonstration of surpassing with a manipulation
}

\author{
Esra Acar, (1) Fatih Hunc, (D) Hale Maral Kir \\ Department of Biochemisty, Kocaeli University, Faculty of Medicine, Kocaeli, Turkey
}

\begin{abstract}
Objectives: Erythrocyte sedimentation rate (ESR) is an elementary and low-cost point of care test commonly used to investigate inflammatory activity, not used for the diagnosis of any particular disease. The present study aims to investigate the diversity in measurements within ESR analyzer modes and demonstrate an alternative manipulation which can reduce the diversity among the modes.

Methods: Measurements were performed in three groups (cycle mode, random mode, manipulation using application of shaker before running random mode) by VISION ESR analyzer on a randomly selected 120 patients' sample from the central laboratory. Statistical analysis was performed with IBM SPSS 20.0 Software. The data were also evaluated using the Bland-Altman method to compare three groups and related subgroups.

Results: In all groups, we found the statistical differences between cycle mode and random mode $(P=0.00)$. In our study, the findings showed that adding the shaker process in random mode yields more optimum results in ESR values, which was higher than $20 \mathrm{~mm} / \mathrm{h}(\mathrm{P}=0.295)$.

Conclusion: According to our analysis, the findings suggest that the compatibility between cycle mode and random mode is weaker; therefore, in clinical laboratory routine, it is preferably recommended to use cycle mode. When operators use random mode, it is more likely recommended, to ensure that the K3-EDTA tubes are exactly mixed with the samples not only manually mixing but also applied shaker process.

Keywords: Automated analyzer, Bland-Altman analysis, cycle mode, erythrocyte sedimentation rate, random mode, EDTA, shaker
\end{abstract}

Point oint of care test is very difficult to provide standardization of benchtop commercial analyzers due to the complexities of optical systems and image retrieval algorithms [1]. These automatic analyzers should be developed and managed with feedback from the clinicians' aspects and observations of users. Operators using automated systems should use various skills and techniques to evaluate and reconstruct processes [2]. Research will allow more analyzer's data to be obtained on this subject. Eventually, standardizing the performance of the automated ESR analyzers is the most challenging, and at the same time, significant issue for clinical laboratory implemen- tation. This substantial responsibility is shared with Clinical Laboratory Standards Institute (CLSl; previously called The National Committee for Clinical Laboratory Standards [NCCLS]) and the International Council for Standardization in Hematology (ICSH) [3].

Measurement of the length of sedimentation reaction in the blood (LSRB), also called erythrocyte sedimentation rate (ESR): expressed in the unit of $\mathrm{mm} / \mathrm{h}$, is a simple and inexpensive test widely used to follow-up treatments and monitoring of diseases as a hematology test in clinical laboratories. Besides that, ESR is a non-specific test that mostly increases in

Address for correspondence: Esra Acar, MD. Department of Biochemisty, Kocaeli University, Faculty of Medicine, Kocaeli, Turkey Phone: +90 5316205990 E-mail: acaresra24@gmail.com ORCID: 0000-0002-0814-0820

Submitted Date: February 24, 2020 Accepted Date: May 23, 2020 Available Online Date: October 05, 2020

${ }^{\circ}$ Copyright 2020 by International Journal of Medical Biochemistry - Available online at www.internationalbiochemistry.com OPEN ACCESS This work is licensed under a Creative Commons Attribution-NonCommercial 4.0 International License. 
diseases, such as infections, inflammations, and malignancies. Despite the limited impact in current clinical practices, ESR measurement has a significant role in temporal arteritis, polymyalgia rheumatica, rheumatoid arthritis. Generally, oncologists request ESR test to monitor patients with Hodgkin Lymphoma on post-chemotherapy period with to determine early relapse [4]. Erythrocyte sedimentation rate levels are higher in female, hypercholesterolemia, and among those living at high altitude and also increase physiologically with age $[5,6]$. Erythrocyte sedimentation rate value up to $15 \mathrm{~mm} / \mathrm{h}$ in males and up to $20 \mathrm{~mm} / \mathrm{h}$ in females is considered normal. In the clinical chemistry practices, the most frequent techniques which performed to measure ESR are Westergren [7] methods diversifying according to the tube size and anticoagulant type $[3,8]$. The analysis is generally carried out by operators manually in the clinics, but there are also automated bench top products worldwide ease to use [3].

The classical Westergren method is a gold standard reference measurement for ESR accepted by The International Council for Standardization in Hematology [9]. The Westergren method has several well-described limitations in routine laboratory practice $[10,11]$. Therefore, automated methods have been developed for ESR measurement, which concludes in a significantly shorter analysis time. In recent years, the newer ESR measurement systems have some potential advantages. The analyzer can work with $1.5 \mathrm{ml}$ blood sample. Users can select from 8, 16, 32 and 64 positions, respectively according to needs. Any closed ethylenediaminetetraacetic acid (EDTA)contain tubes that can be selected for the ESR test to prevent contamination and to ensure biological safety. Results are obtained between 15-30 minutes. These analyzers, which are standardized with commercial control kits, have a good correlation with the golden standard Westergren method. There are some physiological factors that affect ESR measurement, such as red blood cell concentration, hematocrit level, plasma viscosity, plasma proteins containing fibrinogen, albumin and globulins [11, 12]. Also, there are many technical factors during the Westergren methods, such as high levels of in the tube, heparin containing vacutainer preference instead of citrate, holding the tube straight, inadequate shaking of blood, and environment's temperature [12]. Notwithstanding all these, the Westergren method is not very practical in routine laboratory. For instance, a longer time period and a higher volume of blood are required for the analysis [13, 14].

In our clinical laboratory, we use the VISION automated ESR analyzer. This analyzer can run into two different modes, cycle (batch) mode, and random mode. Cycle mode allows the user to place all instances at once. The shaking process is done automatically by the analyzer in this mode and gets results for the whole batch after 20 minutes. Random mode allows users to be added samples at any time to the analyzer, but there is no shaking process in this mode $[11,15]$. Among these modes, it is significant to investigate whether there is a difference between ESR measurement and the optimization of clinic laboratories. When using the random mode, it should be compatible with the cycle mode so that doctors can interpret the clinical evaluation safely. However, to our knowledge, no study has been found comparing the modes of ESR measurement analyzers.

Herein, we examined the compatibility between modes and the performance of this automated system, which is crucial for clinical evaluation. The present study aims to demonstrate the incompatibility between random and cycle modes of automated ESR analyzer and investigate whether if there is a standardized option that can reduce the diversity of ESR measurements.

\section{Materials and Methods}

This research was carried out through the samples of 120 patients, which were simultaneously analyzed on VISION-C (SHENZHEN YHLO BIOTECH CO., Shenzhen, China, 32 samples) automated ESR analyzer. The data were obtained from patients between one to 85 years old prospectively, who were admitted to our hospital between March-August 2018.

Two different modes, cycle mode and random mode, have been applied by the manufacturer to the VISION automated ESR analyzer, that device can preferably run in one of two modes. Cycle mode allows the operator to put in all patients' samples at once and obtain results for the whole batch after 20 minutes. In cycle mode, the tube is placed vertically in one of the slots and the analyzer rotates the tubes 16 times with $180^{\circ}$ angle. The random mode allows the operator to add extra samples at any time even when there are other samples running. Results can be obtained after 20 minutes for each test as the same time in cycle mode. Before placing samples in the analyzer on random mode, as it is strongly recommended to mix the sample manually for about 10 times, but this RM does not shake samples, it was conducted for all samples in random mode [16]. Based on observations, which demonstrate incompatible results for ESR values in random mode, we added a standardized manipulation: shaking process to the random mode in addition to these two modes with the IKA ROLLER 10 Digital at $60 \mathrm{rpm}$. Hereby, ESR was performed in mainly three groups (cycle mode, random mode, and manipulation via application of shaker before running random mode, named as CM, RM, and SM, respectively). Besides, all main groups were also divided into subgroups according to the accepted ESR values less than $20 \mathrm{~mm} / \mathrm{h}$ (groups named as CM1, RM1, and SM1, respectively) and ESR values higher than $20 \mathrm{~mm} / \mathrm{h}$ (groups named as $C M 2, R M 2$, and SM2, respectively). According to the literature, $20 \mathrm{~mm} / \mathrm{h}$ is considered as the upper limit for healthy adults' ESR values. In our research, there are three main groups and with additional subgroups totally nine groups.

In our laboratory, the blood samples are taken into a blood tube containing K3-EDTA fluid for ESR analysis. The minimum sample volume is $1.5 \mathrm{ml}$ for the ESR analyzer. The samples that thoroughly mixed with K3-EDTA fluid are put into the analyzer without delay. With the help of gravity, the erythrocytes begin to collapse, and the clear plasma accumulates in the upper 
part of the tube. The analyzer calculates the sedimentation rate by scanning the intersection of plasma and erythrocytes for a certain time with a moving infrared emitting and receiving $(950 \mathrm{~nm})$. The VISION ESR analyzer measures the distance in $0.25 \mathrm{~mm}$ that is scanning precision, and it has a 100 240V, $50 / 60 \mathrm{~Hz}$ power supply.

The statistical analysis was performed using IBM SPSS 20.0 Software. The normal distribution of the data for the parametric-nonparametric test selection was investigated using statistical evaluation. Wilcoxon signed-rank test and pairwise comparison test were performed in each groups and modes. Spearman correlation analysis was used for nonparametric tests because parametric test assumptions did not meet the normal distribution. The data were also evaluated using the Bland-Altman method [17] to compare three modes and nine groups. The P-value of $0.05(p<0.05)$ was considered significant. Passing and Bablok regression analysis was also used for comparison of each groups and modes.

\section{Ethics}

This prospective study was approved by the Ethics Committee of ***University (Project number: KÜ GOKAEK 2019/135). All authors declare to be in accordance with the ethical standards that defined in the WMA Declaration of Helsinki and ICMJE.

\section{Results}

In this prospective study, the same patient's blood samples were studied in three groups in the same device. The three main groups were also divided into two subgroups with ESR values below $20 \mathrm{~mm} / \mathrm{h}$ and above (Table 1).

All patients' age range was 1-85 and mean of age was $58.32 \pm 14.91$. The patients consisted of 41 males (34.17\%) and 79 females (65.83\%). There were 64 samples in the group less than $20 \mathrm{~mm} / \mathrm{h}$ and 56 samples in the group higher than 20 $\mathrm{mm} / \mathrm{h}$.

The ESR analyzer optimally operates in CM. When our results were evaluated, there was a statistically significant difference between CM and RM ( $p=0.00, n=120)$. In SM group, the mean was slightly closer to CM. When we look at the mean of all groups, the RM mean is higher than the mean of the other groups (Table 1).

In the ESR values less than $20 \mathrm{~mm} / \mathrm{h}$, there was a statistically significant difference between CM1 and RM1 $(p=0.001, n=64)$. There was no statistically significant difference between CM1 and SM1 ( $p=0.06, n=64)$. There was also a statistically significant difference between SM1 and RM1 ( $p=0.04, n=64)$.

In the ESR values higher than $20 \mathrm{~mm} / \mathrm{h}$, there was a statistically significant difference between $C M 2$ and $R M 2(p=0.00, n=56)$. There was no statistically significant difference between CM2

\section{Table 1. Descriptive statistics of each group and mode}

\begin{tabular}{|c|c|c|c|c|c|c|}
\hline & $\mathbf{n}$ & $\min$ & $\max$ & $\begin{array}{l}\text { Median } \\
\text { (25-75 percentile) }\end{array}$ & Mean \pm SD & $\mathbf{p}$ \\
\hline Age & 120 & 1 & 85 & $55.0(41.0-64.75)$ & $58.32 \pm 14.91$ & \\
\hline \multicolumn{7}{|l|}{ Gender } \\
\hline Male & $44(36.6 \%)$ & & & & & \\
\hline Female & $76(63.4 \%)$ & & & & & \\
\hline \multicolumn{7}{|l|}{ Total ESR } \\
\hline CM & 120 & 1.0 & 131.0 & $19.0(10.25-40.75)$ & $23.48 \pm 1.98$ & ${ }^{\mathrm{a}} 0.000$ \\
\hline RM & 120 & 2.0 & 117.0 & $14.0(8.0-36.0)$ & $26.34 \pm 2.10$ & ${ }^{\mathrm{b}} 0.024$ \\
\hline SM & 120 & 2.0 & 133.0 & $18.5(9.0-37.0)$ & $24.78 \pm 2.00$ & ${ }^{\circ} 0.014$ \\
\hline \multicolumn{7}{|l|}{ Gender } \\
\hline Male & 30 (46.9\%) & & & & & \\
\hline Female & $34(53.1 \%)$ & & & & & \\
\hline \multicolumn{7}{|l|}{$<20 \mathrm{~mm} / \mathrm{h}$} \\
\hline CM1 & 64 & 1.0 & 19.0 & $11.5(4.0-16.75)$ & $8.94 \pm 0.63$ & ${ }^{\mathrm{a}} 0.001$ \\
\hline $\mathrm{RM} 1$ & 64 & 2.0 & 21.0 & $9.0(4.0-13.0)$ & $10.44 \pm 0.72$ & ${ }^{\mathrm{b}} 0.04$ \\
\hline SM1 & 64 & 2.0 & 22.0 & $11.0(5.0-13.0)$ & $9.97 \pm 0.69$ & ${ }^{\circ} 0.06$ \\
\hline \multicolumn{7}{|l|}{ Gender } \\
\hline Male & $14(25 \%)$ & & & & & \\
\hline Female & $42(75 \%)$ & & & & & \\
\hline \multicolumn{7}{|l|}{$>20 \mathrm{~mm} / \mathrm{h}$} \\
\hline $\mathrm{CM} 2$ & 56 & 20.0 & 131.0 & $41.0(28.0-57.0)$ & $40.11 \pm 2.87$ & ${ }^{\mathrm{a}} 0.00$ \\
\hline RM2 & 56 & 12.0 & 117.0 & $37.0(21.25-53.0)$ & $44.52 \pm 2.90$ & ${ }^{\mathrm{b}} 0.054$ \\
\hline $\mathrm{SM} 2$ & 56 & 20.0 & 133.0 & $38.0(24.0-56.75)$ & $41.71 \pm 2.83$ & ${ }^{\circ} 0.295$ \\
\hline
\end{tabular}

a: $C M$ \& RM; ${ }^{\text {b: }: R M ~ \& ~ S M ; ~ c: ~ S M ~ \& ~ C M . ~ * ~} p<0.05$, mean $\pm S D$ (SD: Standard deviation). Compared with the non-parametric Wilcoxon signed-rank test 
and SM2 ( $p=0.295, n=56)$. There was not also a statistically significant difference between SM2 and RM2 ( $p=0.054, n=56)$. Although there was no statistical difference, there was a significant difference between the means of SM2 and RM2.

All groups were also analyzed with Bland-Altman graphs shown below in Figure 1.

When the Bland-Altman graphs are drawn separately according to the modes, the ESR results of all the samples measured by $\mathrm{CM}$ and RM are within the confidence interval. However, the mean and confidence interval are higher than the other two Bland-Altman graphs. The mean bias of difference for the Bland-Altman graph was $+2.86 \pm 6.92$ (-10.70 to $+16.4295 \%$ $\mathrm{Cl}$; Confidence Interval). The better accordance was seen between CM and SM. The mean bias was $-1.3 \pm 5.45(-12.00$ to +9.40 95\% Cl) (Fig. 1a).

When the Bland-Altman graphs of the ESR values less than 20 $\mathrm{mm} / \mathrm{h}$ is drawn according to each mode, the compatibility between the modes is almost identical. However, the mean and confidence interval values of the graph drawn for $\mathrm{CM} 1$ and RM1 were higher than the other modes. The mean bias was $+1.5 \pm 3.37$ (-5.13 to+8.13 95\% Cl) (Fig. 1b).

Erythrocyte sedimentation rate values higher than $20 \mathrm{~mm} / \mathrm{h}$ were within the confidence interval in all modes. However, the mean and confidence interval values of the graph drawn for CM2 and RM2 were higher than the other modes. The mean bias was $4.41 \pm 2.29$ (-13.76 to+22.58 95\% Cl) (Fig. 1C). As we can understand from the Bland-Altman analysis, CM2 and SM2 were found to be more compatible than RM2.
Besides, regression analysis of ESR was performed according to all modes. The equation and R2 values of the ESR were shown in Figure 2.

When the regression analysis of all samples was evaluated according to $\mathrm{CM}$, the correlation coefficient between them was almost the same $(n=120$, respectively $r=0.909, C M$ \& RM; $r=0.938, C M \& S M ; r=0.943, R M \& S M)$.

The ESR values less than $20 \mathrm{~mm} / \mathrm{h}$ were evaluated according to $C M 1$, we found the lower correlation between the modes $(r=0.658 \mathrm{CM} 1$ \& RM1; $r=0.707 \mathrm{CM} 1$ \& SM1; $r=0.771 \mathrm{RM} 1$ \& SM1, respectively).

The ESR values higher than $20 \mathrm{~mm} / \mathrm{h}$ were also evaluated according to $\mathrm{CM} 2$, we found the higher correlation between the modes $(r=0.824$ CM 1 \& RM1; $r=0.885$ CM1 \& SM $1 ; r=0.888$ RM1 \& SM1, respectively). When the regression analysis of all modes was evaluated according to $\mathrm{CM}$, we found the lowest correlation between CM and RM.

\section{Discussion}

Recently, new methods and analyzers have been developed to improve the sedimentation measurement procedure and users' safety. The new automated systems are reliable, precise, accurate and easy to use. The automated systems reduce individual dependence in measurement and are preferred concerning safety $[3,18]$.

Recent studies about new ESR analyzers refer that the standardization of sample dilution, degree of mixing, red cell aggregation at the start of the test, and adjustment for environ-
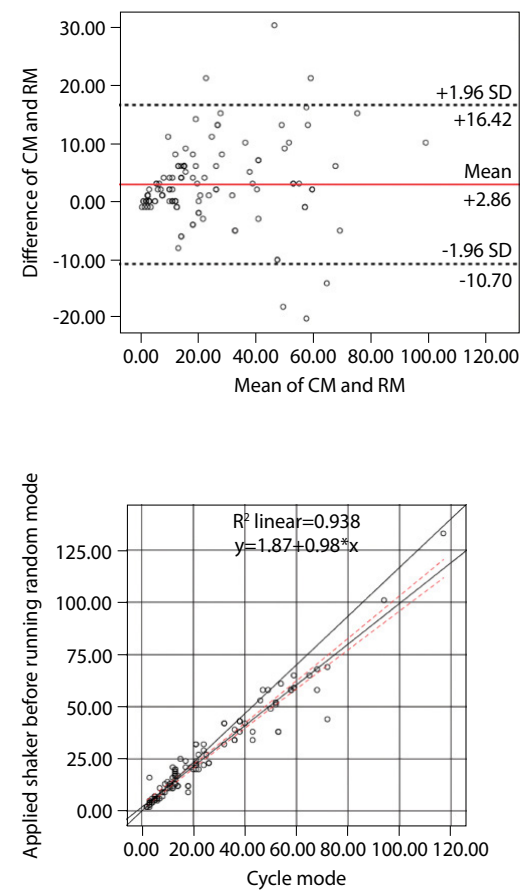
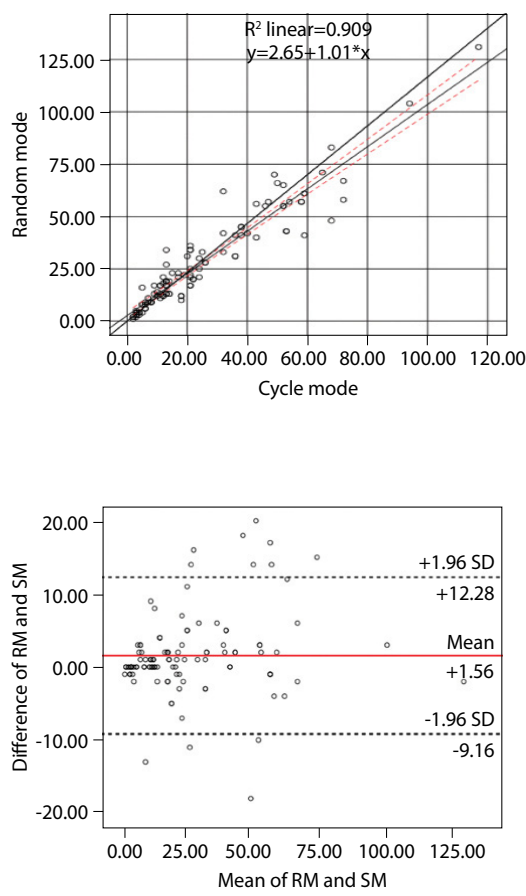
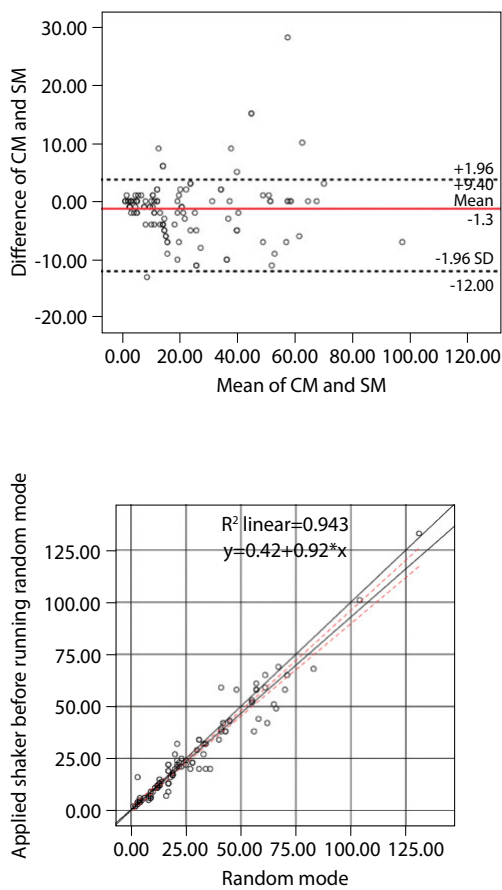

Figure 1. Bland-Altman graphs of the total ESR results of three modes with regression analysis. 


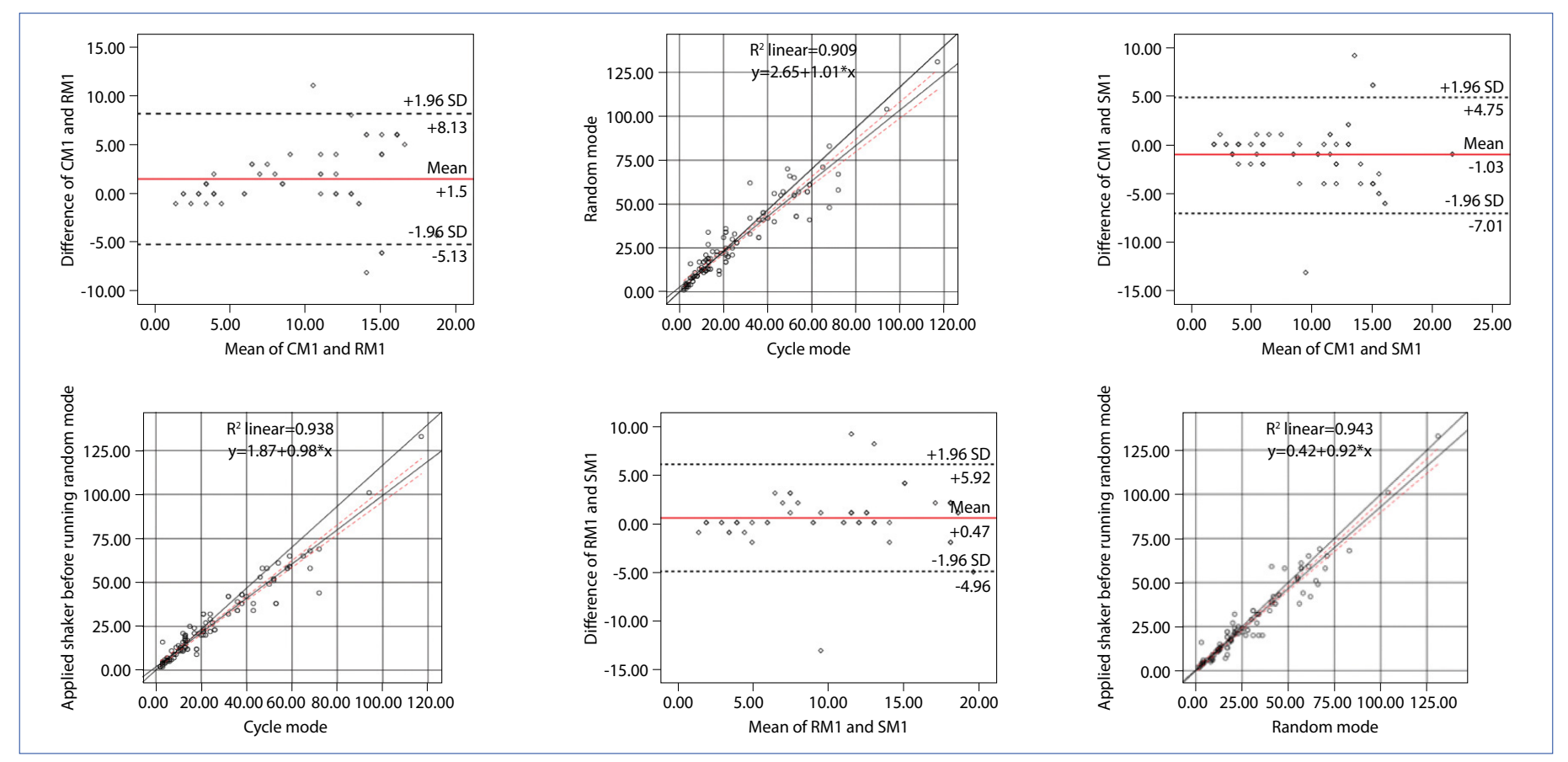

Figure 2. Bland-Altman graphs of the ESR values less than $20 \mathrm{~mm} / \mathrm{h}$ of three modes with regression analysis.
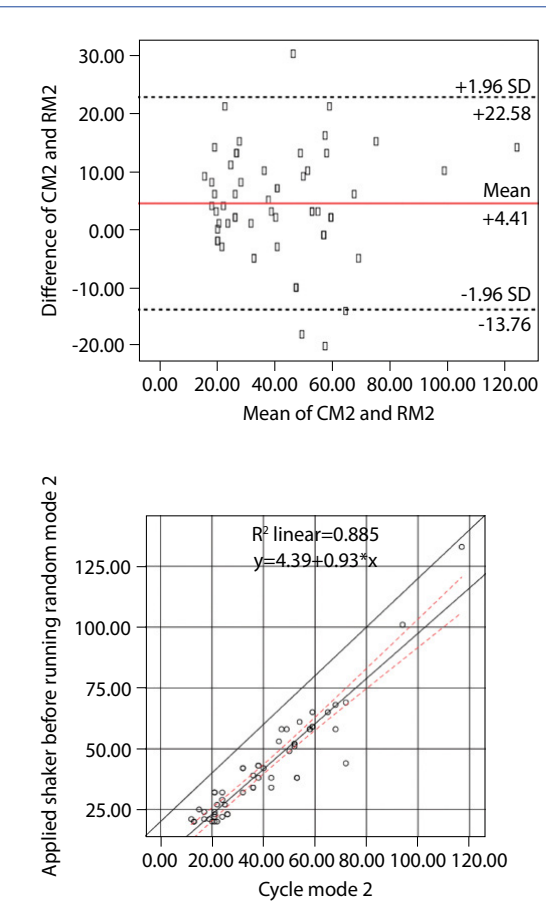
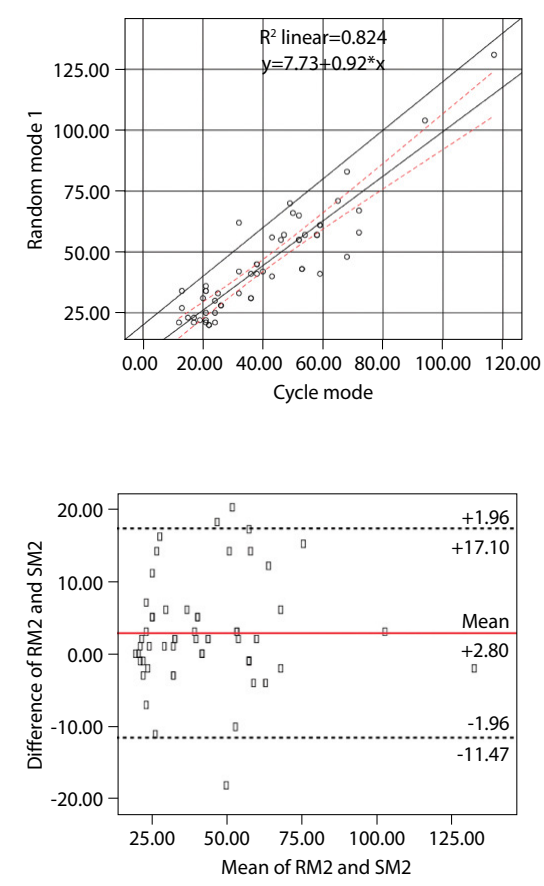
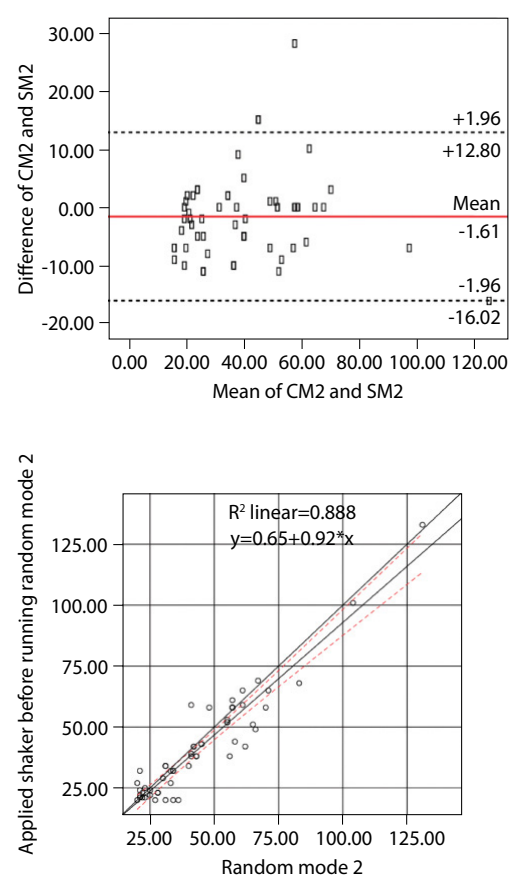

Figure 3. Bland-Altman graphs of the ESR values higher than $20 \mathrm{~mm} / \mathrm{h}$ of three modes with regression analysis.

ment temperature as main improvements. Compared to the 60 minutes required for the Westergren method, results are obtained in 25 minutes; additionally, a $1 \mathrm{ml}$ blood sample is sufficient volume for the ESR autoanalyzer [10]. In most articles about this issue, ESR analyzer methods were compared with the standardized method recommended by ICSH-1993 [18]. Several studies have demonstrated improved precision and high correlation between the reference Westergren method and ESR analyzer [19]. There are also studies in the literature that compare different ESR analyzer [2-4, 20, 21].

Erythrocyte sedimentation rate automated analyzers use undiluted blood samples. However, since the tubes used for the complete blood counts (CBC) can be used, there is no need to take blood from the patient for the second time. Besides, 
researchers have studied on which anticoagulant should be used to obtain optimum results in ESR measurement [22, 23]. K3-EDTA tubes are recommended by ICSH and the National Committee for Clinical Laboratory Standards (NCCLS) as they are more reliable than sodium citrate tubes [3]. Another significant issue is that blood samples are well mixed with anticoagulants. It is recommended that the blood tube is turned up for at least 5-6 times or a mixer device should be used before it is put into the ESR analyzer. VISION ESR analyzer used in our laboratory has a mixing process in $\mathrm{CM}$.

In a study, researchers mentioned that individuals with high ESR ( $>50 \mathrm{~mm} / \mathrm{h}$ ) had low values measured by the automated SE-DI system, whereas individuals with normal ESR had no different values [22]. In other studies, the same results were obtained, and researchers recommended that results were confirmed with the Westergren method, which was the golden standard, because of bias in high ESR level $[23,24]$. In our study, the findings showed that adding a standardized shaker process to the random mode (especially in ESR values higher than $20 \mathrm{~mm} / \mathrm{h}$ ) yields more optimum results ( $p=0.295$, $\mathrm{n}=56$ CM2\&SM2). The mean of RM was higher than the other two modes. As we can see from the Blant-Altman graphs, the mean of the differences between $\mathrm{CM} 2$ and RM2 was close to twice the other modes and the confidence interval has increased. Although the RM value is high, the Blant-Altman results are accepted to be more valuable in evaluating clinic laboratory data [25]. In addition, the blood should be mixed well with the anticoagulant. The mixing in the CM is automatically carried out by rotating $180^{\circ}$ vertically by the analyzer. When we use a shaker in SM, the tubes are rotated horizontally. When we look at our results, the results of the shaker have not reached the desired level with the CM1, which are ESR values lower than $20 \mathrm{~mm} / \mathrm{h}$. However, for ESR values higher than $20 \mathrm{~mm} / \mathrm{h}$, there is no significant difference between CM2 and SM2 results. ( $p=0.295, n=56$ ). The question is why the vertical and horizontal translation of the tubes will make a difference concerning ESR results. Further studies are needed in the future.

In addition to these studies, it is significant to verify whether there is any difference between the modes of these commonly used automated analyzer itself. The clinicians provided feedback for ESR results, which are higher than expected values. The analyzer operators saw abnormalities in the patient result, which was in random mode. Then, the shake process was added to random mode. We saw that the results were slightly close to the CM. While the ESR values were within the normal range, the application of the external roller shake process had no effect in optimizing the ESR measurement, whereas, in ESR $>20 \mathrm{~mm} / \mathrm{h}$, the desired results were obtained. With ESR $>20 \mathrm{~mm} / \mathrm{h}$ roller shaker, there is no difference in cycle mode. Because in our opinion, although the manufacturer warns that the tube should be turned upside down at least 10 times in RM, the interaction of the blood sample with the anticoagulant in the hemogram tube is less. Therefore, the measurement may differ from the ex- pected value. In $\mathrm{CM}$, the interaction with the anticoagulant agent is better and the measurement is more optimal and expected. According to $C M$, the mean $\pm S D$ values of $R M$ in all groups are higher than the other two modes. On the other hands, looking at ESR values less than $20 \mathrm{~mm} / \mathrm{h}$, the addition of shaking process reduced the difference between RM1 and CM1. However, there was no difference between RM1 and SM1. In these groups, the addition of the shaking process could not reach the desired result.

It has been reported in the VISION operation manual book that if the ESR result is higher than $60 \mathrm{~mm} / \mathrm{h}$, there may be a high deviation between the standard results obtained by the Westergren method and those results. Results that are high deviations that should be checked using the Westergren method test [16].

A study in the literature mentioned that further studies evaluating the impacts of alternate ESR methods on clinical diagnosis and management were required for the analyzer standardization [26].

\section{Conclusion}

To our knowledge, this is the first study to investigate the difference between the modes of the VISION automated ESR analyzer, which is used commonly in the laboratories. We can recommend a careful examination and standardization of the results of different modes of ESR analyzer based on our own results.

\section{Limitations of this study}

Erythrocyte sedimentation rate values that higher than 20 $\mathrm{mm} / \mathrm{h}$ can be diluted and read again on the analyzer. The position of the tube is also significant. The barcode should not be in the first place where the light enters the tube.

Due to the design of this research, which is not a method comparison, determination of intraturn and inter-run precision, mean bias and Total Allowable Error (TEa) of VISION automated ESR analyzer have not been implemented and also stability test with the gold standard Westergren method were not carried out.

Conflict of Interest: The authors declare that there is no conflict of interest regarding the publication of this article.

Ethics Committee Approval: This prospective study was approved by the Ethics Committee of ${ }^{* *}$ University (Project number: KÜ GOKAEK 2019/135).

Financial Disclosure: There is no financial disclosure.

Peer-review: Externally peer-reviewed.

Authorship Contributions: Concept - H.M.K.; Design - H.M.K., E.A.; Supervision - H.M.K., F.H.; Funding - None; Materials - H.M.K.; Data collection \&/or processing - H.M.K., E.A.; Analysis and/or interpretation - E.A., F.H.; Literature search - E.A., F.H.; Writing - E.A., F.H.; Critical review - E.A., F.H. 


\section{References}

1. Isiksacan Z, Erel O, Elbuken C. A portable microfluidic system for rapid measurement of the erythrocyte sedimentation rate. Lab Chip 2016;16(24):4682-90. [CrossRef]

2. Shelat SG, Chacosky D, Shibutani S. Differences in erythrocyte sedimentation rates using the Westergren method and a centrifugation method. Am J Clin Pathol 2008;130(1):127-30.

3. Kratz A, Plebani M, Peng M, Lee YK, McCafferty R, Machin SJ; International Council for Standardization in Haematology (ICSH). ICSH recommendations for modified and alternate methods measuring the erythrocyte sedimentation rate. Int J Lab Hematol 2017;39(5):448-57. [CrossRef]

4. Bochen K, Krasowska A, Milaniuk S, Kulczyńska M, Prystupa A, Dzida G. Erythrocyte sedimentation rate - an old marker with new applications. J Pre Clin Clin Res 2011;5(2):50-5.

5. Sezer S, Yilmaz FM, Kaya O, Uysal S. Evaluation of Ves-Matic Cube 200 for erythrocyte sedimentation rate determination. J Clin Lab Anal 2013;27(5):367-72. [CrossRef]

6. Miao G. Reference values of erythrocyte sedimentation rate of adult healthy subjects. Arch Med Res 2002;33(5):506-9. [CrossRef]

7. Westergren $A$. The technique of the red cell sedimentation reaction. Am Rev Tuberc 1926;14(1):94-101.

8. Hashemi R, Majidi A, Motamed H, Amini A, Najari F, Tabatabaey A. Erythrocyte Sedimentation Rate Measurement Using as a Rapid Alternative to the Westergren Method. Emerg (Tehran) 2015;3(2):50-3.

9. Lapić I, Piva E, Spolaore F, Tosato F, Pelloso M, Plebani M. Automated measurement of the erythrocyte sedimentation rate: method validation and comparison. Clin Chem Lab Med 2019;57(9):1364-73. [CrossRef]

10. Ozdem S, Akbas HS, Donmez L, Gultekin M. Comparison of TEST 1 with SRS 100 and ICSH reference method for the measurement of the length of sedimentation reaction in blood. Clin Chem Lab Med 2006;44(4):407-12. [CrossRef]

11. VISION Automatic ESR Analyzer. Available at: http://www.unimedica.net/images/uploads/products/1435050727649.pdf. Accessed Feb 10, 2019.

12. Romero A, Muñoz M, Ramírez G. Length of sedimentation reaction in blood: a comparison of the test 1 ESR system with the ICSH reference method and the sedisystem 15. Clin Chem Lab Med 2003;41(2):232-7. [CrossRef]

13. Choi JW, Pai SH. Influences of hypercholesterolemia on red cell indices and erythrocyte sedimentation rate in elderly persons. Clin Chim Acta 2004;341(1-2):117-21. [CrossRef]
14. Hardeman MR, Levitus M, Pelliccia A, Bouman AA. Test 1 analyser for determination of ESR. 1. Practical evaluation and comparison with the Westergren technique. Scand J Clin Lab Invest 2010;70(1):21-5. [CrossRef]

15. VISION ESR Analyzer Operation Manual V2.2. Available at: http:// www.h3diagnostics.com/product/vision/ Accessed Jul 18, 2019.

16. Lab \& Health Supply - VISION - YHLO. Available at: https:// www.youtube.com/watch? $v=0 C A 2 \_F X P G R g \& t=188 \mathrm{~s}$. Accessed Aug 10, 2019.

17. Bland JM, Altman DG. Statistical methods for assessing agreement between two methods of clinical measurement. Lancet 1986; 1(8476):307-10. [CrossRef]

18. Happe MR, Battafarano DF, Dooley DP, Rennie TA, Murphy FT, Casey TJ, et al. Validation of the Diesse Mini-Ves erythrocyte sedimentation rate (ESR) analyzer using the Westergren ESR method in patients with systemic inflammatory conditions. Am J Clin Pathol 2002;118(1):14-7. [CrossRef]

19. Mahlangu JN, Davids M. Three-way comparison of methods for the measurement of the erythrocyte sedimentation rate. J Clin Lab Anal 2008;22(5):346-52. [CrossRef]

20. Boğdaycioğlu N, Yilmaz FM, Sezer S, Oğuz E. Comparison of iSED and Ves-Matic Cube 200 Erythrocyte Sedimentation Rate Measurements With Westergren Method. J Clin Lab Anal 2015;29(5):397-404. [CrossRef]

21. Curvers J, Kooren J, Laan M, van Lierop E, van de Kerkhof D, Scharnhorst V, et al. Evaluation of the Ves-Matic Cube 200 erythrocyte sedimentation method: comparison with Westergren-based methods. Am J Clin Pathol 2010;134(4):653-60.

22. AlFadhli SM, Al-Awadhi AM. Comparison of erythrocyte sedimentation rate measurement by the automated SEDIsystem and conventional Westergren method using the Bland and Altman statistical method. Med Princ Pract 2005;14:241-4.

23. Öztürk G, Özdemir Ş, Altuntaş A, Akyol S, Bulut E, Erden G, et al. Comparison of two different methods for the determination of erythrocyte sedimentation rate. Journal of Clinical \& Experimental Investigations 2014;5(3):371-5. [CrossRef]

24. Ranjan S and Wahab MA. A Comparative Study of Erythrocyte Sedimentation Rate by Automated ESR Analyser and Manual Westergren's Method. Saudi J Pathol Microbiol 2018;3(1):44-6.

25. Giavarina D. Understanding Bland Altman analysis. Biochem Med (Zagreb) 2015;25(2):141-51. [CrossRef]

26. Schapkaitz E, RabuRabu S, Engelbrecht M. Differences in erythrocyte sedimentation rates using a modified Westergren method and an alternate method. J Clin Lab Anal 2019;33(2):e22661. 